Article

\title{
Identification of the Red-Necked Longhorn Beetle Aromia bungii (Faldermann, 1835) (Coleoptera: Cerambycidae) with Real-Time PCR on Frass
}

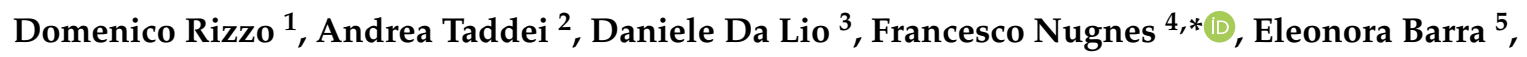 \\ Luciana Stefani ${ }^{1}$, Linda Bartolini ${ }^{1}$, Raffaele V. Griffo ${ }^{6}$, Paola Spigno ${ }^{7}$, Lucia Cozzolino ${ }^{7}$, \\ Elisabetta Rossi ${ }^{3}$ (I) and Antonio P. Garonna ${ }^{5}$ \\ 1 Laboratory of Phytopathological Diagnostics and Molecular Biology, Plant Protection Service of Tuscany, \\ 51100 Pistoia, Italy; domenico.rizzo@regione.toscana.it (D.R.); stefani.luciana@libero.it (L.S.); \\ linda.bartolini@regione.toscana.it (L.B.) \\ 2 ANSES Plant Health Laboratory, Entomology and Invasive Plants Unit, 34988 Montferrier-sur-Lez CEDEX, \\ France; andrea.taddei@anses.fr \\ 3 Department of Agricultural, Food and Agro-Environmental Sciences, University of Pisa, 56124 Pisa, Italy; \\ daniele.dalio@hotmail.com (D.D.L.); elisabetta.rossi@unipi.it (E.R.) \\ 4 National Research Council (CNR), Institute for Sustainable Plant Protection, 80055 Portici, Italy \\ 5 Department of Agricultural Sciences, University of Naples Federico II, 80055 Portici, Italy; \\ eleonora.barra@unina.it (E.B.); garonna@unina.it (A.P.G.) \\ 6 Plant Protection Service of Campania, Centro Direzionale, 80124 Napoli, Italy; \\ raffaele.griffo@regione.campania.it \\ 7 Phytopathological Laboratory, Campania Region, 80141 Napoli, Italy; \\ paola.spigno@regione.campania.it (P.S.); lucia.cozzolino@unina.it (L.C.) \\ * Correspondence: francesco.nugnes@ipsp.cnr.it; Tel.: +39-0817-7536-5810
}

Received: 10 June 2020; Accepted: 24 July 2020; Published: 28 July 2020

\begin{abstract}
Aromia bungii (Faldermann, 1835) (Coleoptera: Cerambycidae), the red-necked longhorn beetle is native to eastern Asia, where it is an important wood-borer of fruit and ornamental species of the genus Prunus. A. bungii is a quarantine pest in the European Union, following its accidental introduction and establishment in Germany and Italy, and is currently included in the list of priority pests. To confirm its infestations in outbreak areas, adult or larval specimens are needed to perform morphological or molecular analyses. The presence of $A$. bungii larvae inside the attacked trees makes the collection of specimens particularly difficult. Thus, we present two diagnostic protocols based on frass analysis with real-time PCR (probe and SYBR Green). The results obtained show that a non-invasive approach for detecting the presence of this harmful invasive pest can be a reliable and accurate alternative diagnostic tool in phytosanitary surveys, as well as to outline a sustainable pest management strategy.
\end{abstract}

Keywords: frass DNA; non-invasive diagnostic tool; phytosanitary survey; quarantine pest; xylophagous insect

\section{Introduction}

The red-necked longhorn beetle (RLB) Aromia bungii (Faldermann, 1835) (Coleoptera: Cerambycidae) is a destructive wood-borer native to the eastern Palearctic region (Mongolia, China, Indochinese peninsula) [1]. In the last decade, the species spread out, becoming established in Germany [2-4], Italy [5-7], and Japan [8,9]. Its economic importance in its invasion areas is related to its wide polyphagy which includes many ornamental and cultivated woody species of the genus 
Prunus. However, some evidence that has yet to be verified, seems to indicate many other host plants that belong to Oleaceae, Juglandaceae, Salicaceae and other families [10,11]. RLB females lay their eggs in the bark crevices of the trunks and main branches of their host plants; the larvae bore galleries, determining structural weaknesses and causing dieback until the death of trees in many cases [12]. In native areas, RLB has several overlapping generations per year [13]. Some of its biological traits were recently highlighted in a study on the Italian population [14]. According to these observations, RLB has impressive fertility and longevity.

Due to the risk and impact factors posed by this pest, in the EU territory, the RLB is a quarantine priority pest included in the Annex of Regulations UE 1702/2019. The relevant containment measures require the destruction of the infested trees and severe regulations or restrictions on the local trade of host plants and timber [15-17]. These eradication measures codified by EU Decision no. 1503, 2018, economically impact nurseries, farmers and their related activities [18].

The common prevention/eradication strategies for RLB are based on a visual inspection of symptomatic plants showing the presence of adult exit holes and/or larval frass at the foot of the tree. However, due to the unspecific symptoms of the attack, this method of identification is extremely unprecise and can lead to misleading diagnoses [11]. Moreover, the collection of larvae generally entails serious injury to the host plant up to its felling, with serious economic consequences in terms of time and plant damage. The use of frass, which is present outside the host plant or easily collectable in the outer part of insect galleries, could be a solution to these negative aspects.

The application of a non-invasive diagnostic technique such as DNA extraction from frass, has been used on several xylophagous insects for discrimination at the species level [19-24].

A protocol based on PCR using the DNA extracted from the fecal material present in the frass of Anoplophora chinensis Forster (1771) (Coleoptera: Cerambycidae), provided a potential diagnostic tool in support of phytosanitary surveys [25].

In the present study, we developed two diagnostic protocols based on real-time PCR (Probe and SYBR Green) to confirm the presence of RLB on host plants using frass samples collected in the field. This comparative study seeks to determine and standardize the most reliable method to discriminate infestations of invasive RLB and those of other alien or autochthonous xylophagous species. The accurate identification of RLB infestations would be crucial in defining a prompt, localized, and, consequently, environmentally sound pest management project.

\section{Materials and Methods}

\subsection{Insect and Frass Samples Used for DNA Extraction}

From February to March 2018, capillary monitoring activity was carried out in several farms situated in the infested areas around Naples where RLB had been reported (NW: 33T, 4,524,705 m N, 432,703 m E, $327 \mathrm{~m}$ a.s.l.; NE: 33T, 4,524,701 m N, 434,806 m E, $248 \mathrm{~m}$ a.s.l.; SW: 33T, 4,521,725 m N, 430,859 m E, $133 \mathrm{~m}$ a.s.l.; SE: 33T, 4,522,185 m N, 433,509 $\mathrm{m} \mathrm{E,} 152 \mathrm{~m}$ a.s.l.). These inspections highlighted the presence of several suffering stone fruit trees showing holes on their trunks and the accumulation of frass near the tree foot. Frass samples were singularly collected in sterile $50 \mathrm{~mL}$ plastic vials and suitably labeled. Additional samples of frass from an RLB outbreak in Lombardy $(32 \mathrm{~T}, 5,036,660 \mathrm{~m} \mathrm{~N}$, 497,386 m E; $144 \mathrm{~m}$ a.s.l.) were also collected. Each adult or larval specimen was preserved in $70 \%$ absolute ethanol, while the frass samples were stored at room temperature in plastic vials. Each frass sample collected directly from the host plants was categorized accordingly as adult or immature. The larval stages were identified using the appropriate morphological keys [26-28].

Molecular characterizations were occasionally carried out with species specific primers (data not shown) to confirm the morphological identifications. Frass samples produced by other species of xylophagous pests were also collected as non-target specimens. DNA was extracted from the target samples; the non-target samples collected in the field and DNA from the entomological biomolecular 
collection of the phytopathological laboratory of the Phytosanitary Service of the Tuscany Region were also used (Table 1).

Table 1. List of target and non-target specimens used in this study $(\mathrm{A}=$ adult, $\mathrm{L}=$ larva, $\mathrm{E}=\mathrm{egg}, \mathrm{F}=$ frass $)$.

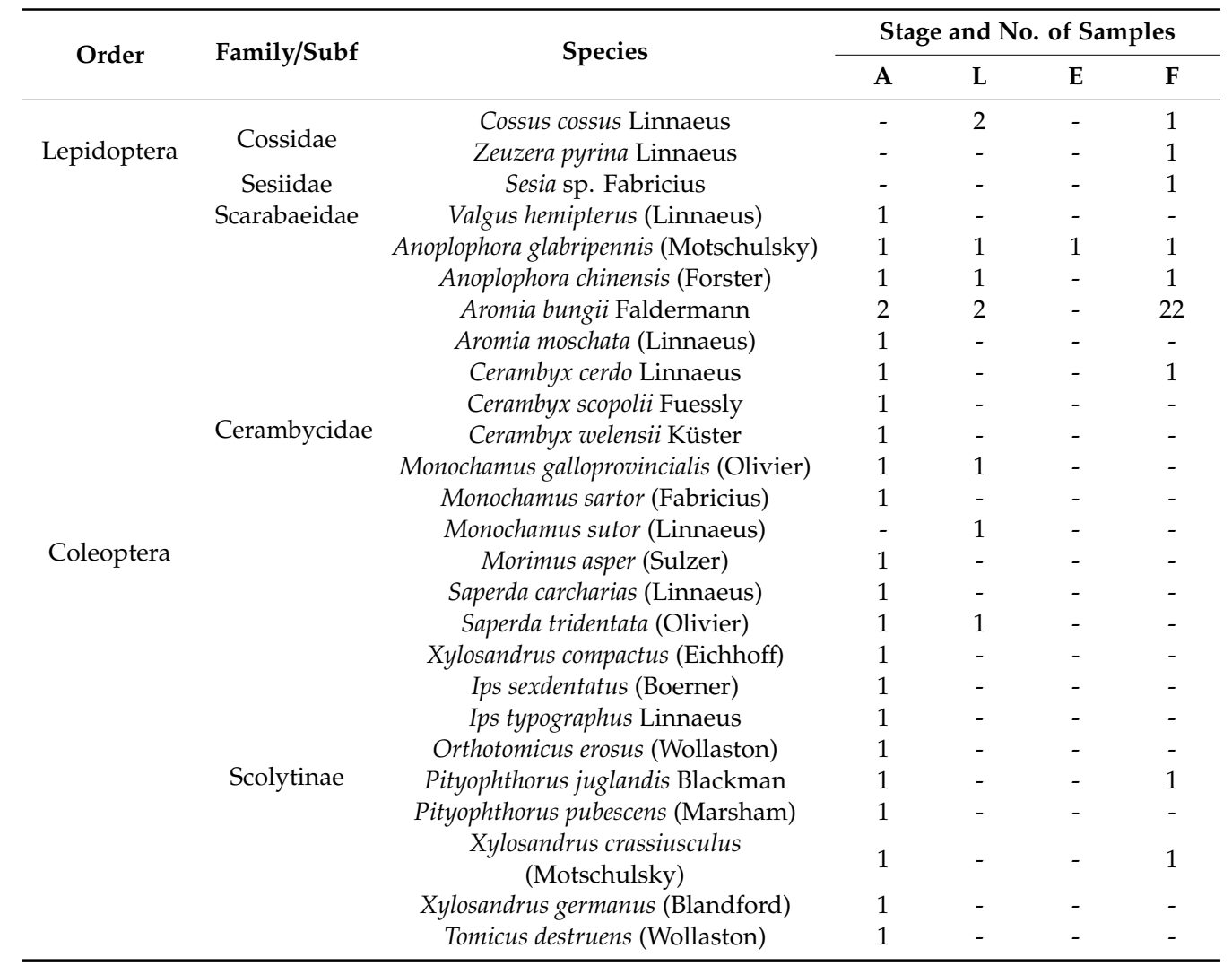

Four elder samples of RLB frass collected in 2013 and 2014 and stored at room temperature were also processed to evaluate the DNA degradation over time.

\subsection{DNA Extraction}

\subsubsection{DNA Extraction from Frass}

The DNA extraction protocols were each tested on all frass samples reported in Table 1. In the case of frass, the first step of the extraction protocol required sample homogenization. About $1 \mathrm{~g}$ of frass was processed in a Mixer Mill MM 200 (Retsch, Torre Boldone, Italy) homogenizer in $10 \mathrm{~mL}$ steel jars at a high speed (30 oscillations/s) for $30 \mathrm{~s}$. The method suggested by Li [29] was applied until the addition of chloroform and subsequent centrifugation. After centrifugation, $600 \mu \mathrm{L}$ of the supernatant was purified using the Maxwell ${ }^{\circledR}$ RSC PureFood GMO purification kit and authentication kit provided with the automated purificator MaxWell 16 (Promega, Madison, WI, USA) according to the manufacturer's protocol (catalog number selected: AS1600). The quantization and contamination degree evaluations of the extracted DNA were performed using the QiaExpert (Qiagen, Hilden, Germany) instrument.

DNA extracted from the frass was studied in real-time PCR reactions using a TaqMan dual-labeled probe targeting a highly conserved region of the cytochrome oxidase gene as described in [30]. This test allowed us to confirm the integrity and the quality of the extracted DNA.

\subsubsection{DNA Extraction from Insects}

Each RLB sample was used as a matrix for DNA extraction. Genomic DNA was extracted using the CTAB extraction method reported in [29] with slight modifications. The DNA was eluted in $100 \mu \mathrm{L}$ 
of nuclease-free water and used for real-time PCR reactions immediately or stored at $-20^{\circ} \mathrm{C}$ until use. The quantization and contamination degree evaluations of the extracted DNA were performed using the QiaExpert (Qiagen, Hilden, Germany) instrument. To assess the quality of the DNA extracted from the insects, 1:20 DNA/dds $\mathrm{H}_{2} \mathrm{O}$ was tested in a real-time PCR reaction using a dual-labeled probe targeting a highly conserved region of the $18 \mathrm{~S}$ rDNA [31]. The amplifiability tests carried out in this way, both for frass and for insect stages, served as a control for the extractions and allowed us to verify the presence of inhibitors through the detected $\mathrm{Ct}$ and the slope of the relative amplification curves.

\subsection{Design of the Primers and Probes for the TaqMan Probe and SYBR Green Real-Time Tests}

A uniform primer design approach was applied in the development of all primer pairs for real-time PCR using the probe, as well as for SYBR Green. The primer pairs and probes were designed preferentially within the mitochondrial conserved region sequences of the RLB using the OligoArchitect ${ }^{\mathrm{TM}}$ Primers and Probe Online software (Sigma-Aldrich, St. Louis, MO, USA) with the following specifications: a 80 to $200 \mathrm{bp}$ product size, a Tm (melting temperature) of 55 to $65^{\circ} \mathrm{C}$, primer length of 18 to $22 \mathrm{bp}$, and absence of secondary structure when possible. The primers/probes used in this study for the real-time TaqMan and SYBR Green protocols are reported in Table 2.

Table 2. Primers and probes of the real-time PCR tested.

\begin{tabular}{cccccc}
\hline $\begin{array}{c}\text { Primer/Probe } \\
\text { Name }\end{array}$ & $\begin{array}{c}\text { Length } \\
\text { (Bases) }\end{array}$ & Sequence 5' '3' $^{\prime}$ & $\begin{array}{c}\text { Nucleotide } \\
\text { Position }\end{array}$ & $\begin{array}{c}\text { Product } \\
\text { Size (bp) }\end{array}$ & $\begin{array}{c}\text { Reference } \\
\text { Sequence }\end{array}$ \\
\hline Abungii_285F & 22 & CAGCAGTTCTTCTTTTATTATC & 285 to 307 & 199 & DQ223728 \\
Abungii_484R & 18 & GGTGTCCAAAGAATCAAA & 484 to 502 & & \\
Abungii_309P & 26 & FAM_TACCAGTATTAGCAGGAGCCATTACG_BHQ1 & 309 to 335 & & JQ904852 \\
Abungii_436F & 22 & TAACTTCCGTCTATTAGATGTA & 436 to 458 & 157 & \\
Abungii_592R & 18 & GCTAACTTGGTTGATTCG & 592 to 610 & & \\
\hline
\end{tabular}

An in silico test of the primer pairs was then performed with the BLAST ${ }^{\circledR}$ (Basic Local Alignment Search Tool (Bethesda, MD, USA-http://www.ncbi.nlm.nih.gov/BLAST) software to assess the specificity of the designed primer pairs.

To further assess the specificity in silico, the nucleotide sequences related to the qPCR Probe (285F/309P/484R) and SYBR Green (436F/592R) were aligned using the MAFFT program [32] implemented within the Geneious 10.2.6 [33] software (Biomatters, Auckland, New Zealand—http: //www.geneious.com) (Figures 1 and 2).

In both cases (SYBR Green and TaqMan PCR real-time protocols), temperatures ranging from $52^{\circ} \mathrm{C}$ to $60{ }^{\circ} \mathrm{C}$ were used to determine the optimal annealing temperatures. The concentrations of the oligos and probe were tested at $0.2 \mu \mathrm{M}, 0.3 \mu \mathrm{M}$, and $0.4 \mu \mathrm{M}$ for the oligos and $0.1 \mu \mathrm{M}, 0.2 \mu \mathrm{M}$, and $0.3 \mu \mathrm{M}$ for the probe. The different reagents used to evaluate the robustness of the methods (different master mixes from different companies) in the two real-time PCR protocols were then compared. In particular, the Quanti Nova MasterMix Probe (Qiagen, Hilden, Germany) was compared with the iTAQ MasterMix (Biorad, Hercules, CA, USA) in the qPCR Probe protocol, while in the qPCR SYBR Green protocol, the master mixes SsoAdvanced Universal SYBR Green Supermix (Biorad, Hercules, CA, USA) were tested against those of Quanti Nova Mastermix SYBR Green (Qiagen, Hilden, Germany). We also used different thermal cyclers: CFX96 (Biorad, Hercules, CA, USA), Aria MMX (Agilent, Santa Clara, CA, USA), and Rotor Gene (Qiagen, Hilden, Germany), and different operators that alternated in the various operations of nucleic acid extraction and gene amplification.

The qPCR Probe and SYBR Green protocols that were tested for target and non-target organisms highlighted inclusivity and exclusivity (diagnostic specificity) on the different analyzed matrixes/templates. 


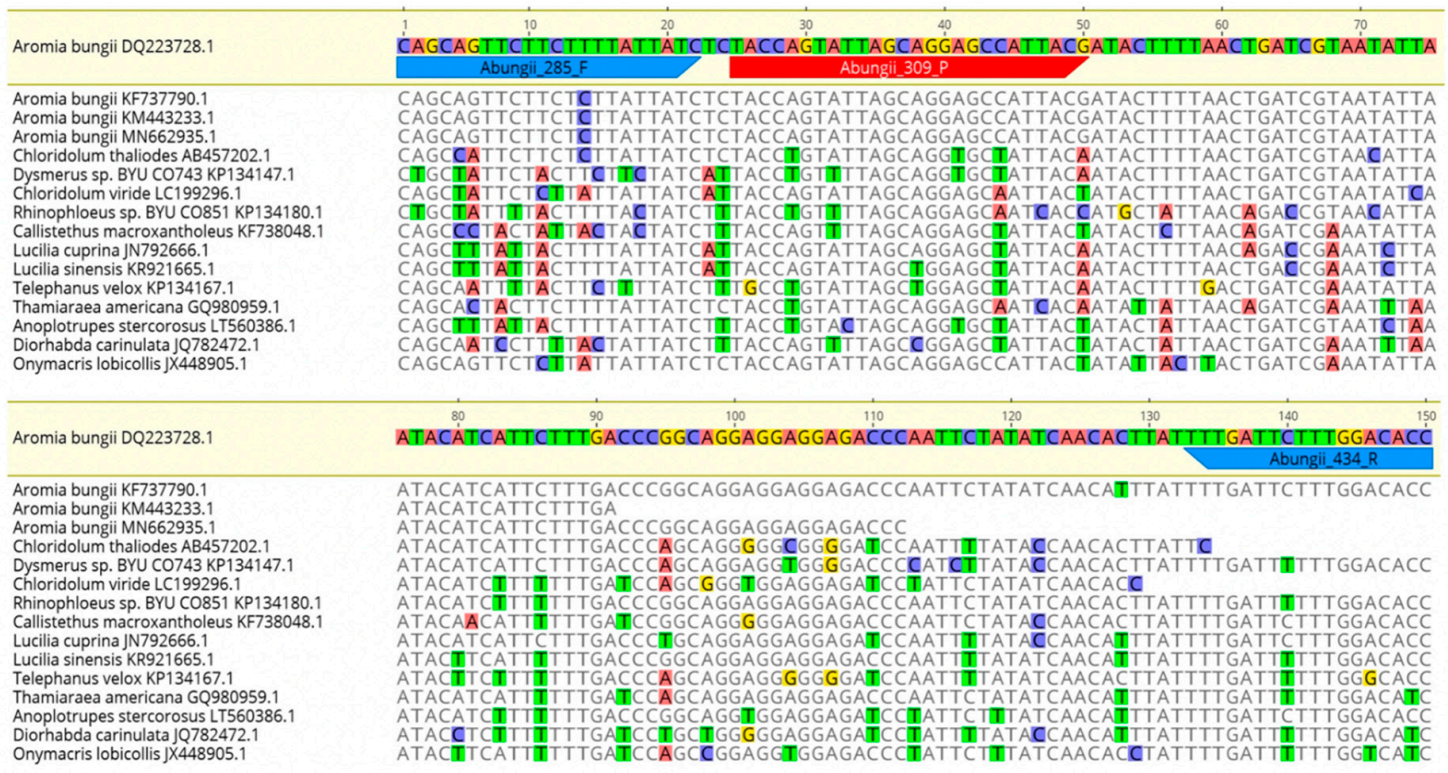

Figure 1. Alignment resulting from the in silico amplicon of $A$. bungii using the probe-based method and the similar sequences of the organisms present in GenBank.

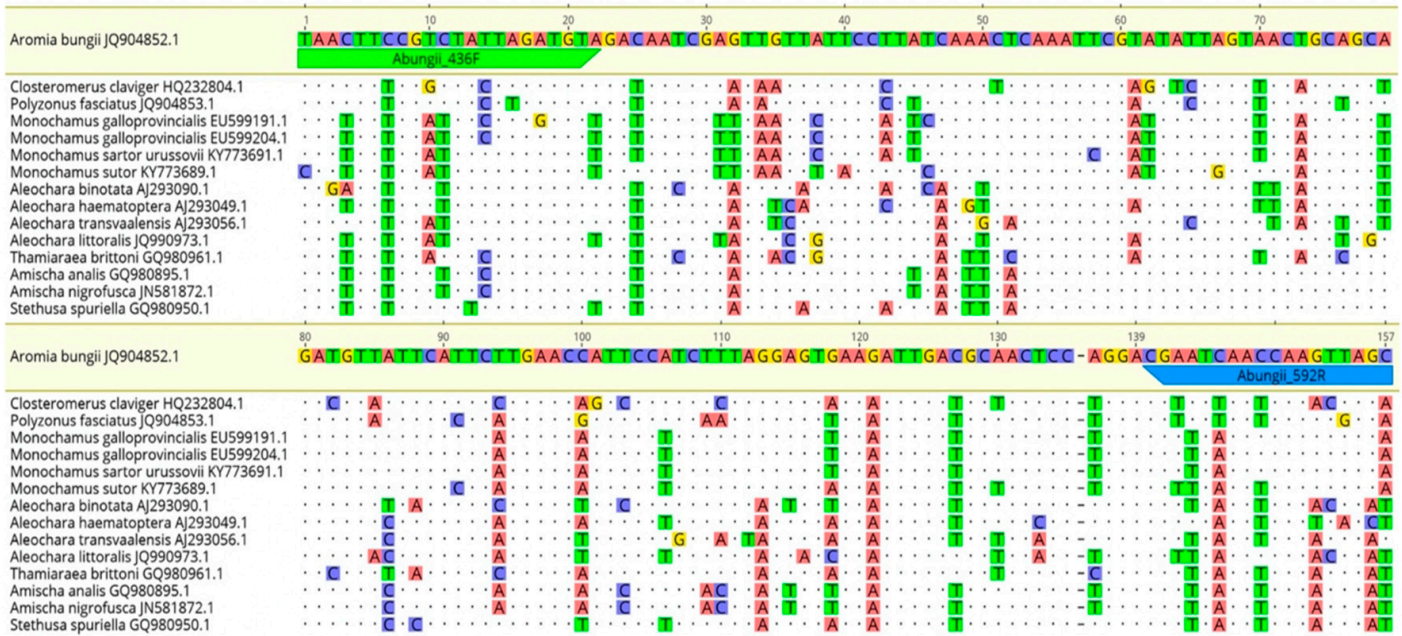

Figure 2. Alignment resulting from the in silico amplicon of A. bungii using the SYBR Green-based method and the similar sequences of the organisms present in GenBank.

\subsection{Blind Panel Validation of the Assay}

To validate the qPCR real-time data of the developed tests, 32 frass sub-samples from 5 wood-boring species (A. bungii, Anoplophora chinensis, An. glabripennis, Cossus cossus and Sesia sp.) were used for a blind panel test.

The tests were carried out in three different laboratories: phytosanitary laboratories from the Tuscany (Lab 1), Campania (Lab 2), and Lombardy regions (Lab 3).

All DNA samples were previously diluted at a final concentration of $5 \mathrm{ng} / \mu \mathrm{L}$. The samples were tested in duplicate, and no template controls were included. As part of this blind panel, the true positive, false negative, false positive, and true negative parameters were evaluated according to the requirements outlined in the EPPO standards [34,35].

The set of 32 samples included 24 samples of RLB, 3 of C. cossus, 2 of An. chinensis, 2 of An. glabripennis, and 1 of Sesia sp. The test was performed in blind. The samples were then packed in solid $\mathrm{CO}_{2}$ and air-freighted. The laboratories involved were also supplied with the same master mix for 
the qPCR reactions (Quanti Nova Mastermix for SYBR Green and Quanti Nova MasterMix for the Probe, Qiagen, Hilden, Germany), primers, and probes. In total, $100 \mu \mathrm{L}$ of each extracted DNA (at a concentration of $5 \mathrm{ng} / \mu \mathrm{L}$ ) was sent to the involved laboratories. In all three laboratories, the parameters for true positives, false negatives, false positives and true negatives were taken into account $[35,36]$.

\subsection{Repeatability and Reproducibility}

The repeatability and reproducibility were also estimated during this study based on the internal data we obtained. Standard parameters such as the cycle quantification (Cq), mean and standard deviation, and the percentage coefficient of variation ( $\% \mathrm{CV}$ ) were considered to calculate the intra-run variation (repeatability) and inter-run variation (reproducibility).

To estimate the repeatability, we tested ten samples in triplicate in two separate runs and calculated the $\%$ CV for each sample. To estimate reproducibility, the data of the two runs were compared $[37,38]$.

\subsection{Limit of Detection (LoD)}

For each methodology used in the experimental design, the LoD was estimated using a 10-fold 1:5 serial dilution with artificial frass $(100 \mathrm{ng} / \mu \mathrm{L})$ obtained by adding frass from another species (in this case, An. chinensis) to $10 \mathrm{ng} / \mu \mathrm{L}$ of RLB DNA larvae. Each dilution was tested in triplicate.

\subsection{Data Analysis}

Under qPCR and SYBR Green PCR amplification, the raw data were analyzed using the CFX Maestro 1.0 software (Biorad, Hercules, CA, USA). The DNA concentration, OD ratio, and repeatability/reproducibility results were analyzed statistically using descriptive parameters (CV\% and SD) via SPSS version 26.0 (SPSS Inc., Chicago, IL, USA). The same software was used for statistical investigations of the blind panel, which focused on the variability between average values compared to the expected values using a Fisher test ( $95 \%$ confidence interval and defined degrees of freedom).

\section{Results}

\subsection{DNA Extraction from Frass and Insects}

The extraction protocol for frass (CTAB 2\% + MaxWell16) performed very well. High-quality and high-quantity DNA was extracted with an average concentration of $86 \pm 4 \mathrm{ng} / \mu \mathrm{L}$ (SD) and an average $260 / 280 \mathrm{~nm}$ absorbance ratio of $1.93 \pm 0.1$ (SD). The efficiency of the extraction protocol was confirmed by a real-time PCR (COX) probe with an average Cq of $16.28 \pm 1.95$ (SD).

Similarly, the protocol of DNA extraction from the insect bodies was efficient. The mean concentrations were $221 \pm 83.26 \mathrm{ng} / \mu \mathrm{L}$ (SD) and $162 \pm 4.49 \mathrm{ng} / \mu \mathrm{L}$ (SD) for the larvae and adults, respectively, while the $260 / 280 \mathrm{~nm}$ absorbance ratios were $1.98 \pm 0.22$ (SD) and $2.1 \pm 0.17$ (SD) for the larvae and adults, respectively.

The DNA extracts from the larvae and adults of RLB were perfectly amplified with a mean Cq value of $15.12 \pm 1.74(\mathrm{SD})$.

\subsection{Optimization of the Diagnostic Methods for RLB}

The optimal annealing temperatures were $55^{\circ} \mathrm{C}$ and $58^{\circ} \mathrm{C}$ for SYBR Green and TaqMan real-time PCR, respectively. For the qPCR SYBR Green protocol, the melting peak was around $79^{\circ} \mathrm{C} \pm 0.5^{\circ} \mathrm{C}$. The optimized reactions needed a primer and probe concentration of $0.4 \mu \mathrm{M}$ and $0.2 \mu \mathrm{M}$, respectively. However, in the case of the qPCR SYBR Green assay, a non-specificity of $\mathrm{Cq}>34$ was found for X. crassiusculus, although differentiation was possible because the melting peak was different.

\subsection{Blind Panel Validation of the Assay}

The results obtained from ring tests performed by the three labs testing the qPCR Probe and the qPCR SYBR Green protocols are reported in Table 3. 
Table 3. The positive (+) and negative (-) results of the qPCR Probe and SYBR Green protocols applied in the ring test carried out in the three laboratories. Cq (cycle quantification); Res (result); Und (not determinable); N/A (not amplified).

\begin{tabular}{|c|c|c|c|c|c|c|c|c|c|c|c|c|c|c|c|}
\hline \multirow{3}{*}{ N. } & \multirow{3}{*}{ Expected Result } & \multicolumn{7}{|c|}{ qPCR Probe Protocol } & \multicolumn{7}{|c|}{ qPCR SYBR Green Protocol } \\
\hline & & \multicolumn{2}{|c|}{ Lab 1} & \multicolumn{2}{|c|}{ Lab 2} & \multicolumn{2}{|c|}{ Lab 3} & \multirow{2}{*}{$\mathrm{Cq}$ Mean $\pm \mathrm{SD}$} & \multicolumn{2}{|c|}{ Lab 1} & \multicolumn{2}{|c|}{ Lab 2} & \multicolumn{2}{|c|}{ Lab 3} & \multirow{2}{*}{$\mathrm{Cq}$ mean $\pm \mathrm{SD}$} \\
\hline & & $\mathrm{Cq}$ & Res. & $\mathrm{Cq}$ & Res. & $\mathrm{Cq}$ & Res. & & $\mathrm{Cq}$ & Res. & $\mathrm{Cq}$ & Res. & $\mathrm{Cq}$ & Res. & \\
\hline 1 & + & 25.11 & + & 24.78 & + & 24.37 & + & $24.38 \pm 0.37$ & 22.65 & + & 25.37 & + & Und & + & $24.01 \pm 1.92$ \\
\hline 2 & + & 28.6 & + & 28.48 & + & 26.96 & + & $26.96 \pm 0.91$ & 26.48 & + & 26.29 & + & Und & + & $26.39 \pm 0.13$ \\
\hline 3 & + & 28.93 & + & 28.67 & + & 29.78 & + & $29.78 \pm 0.58$ & 29.29 & + & 26.78 & + & Und & + & $28.04 \pm 1.77$ \\
\hline 4 & + & 29.81 & + & 30.53 & + & 26.96 & + & $29.10 \pm 1.89$ & 29.31 & + & 26.96 & + & Und & + & $28.14 \pm 1.66$ \\
\hline 5 & + & 30.27 & + & 30.7 & + & 27.21 & + & $29.39 \pm 1.90$ & 29.47 & + & 27.21 & + & Und & + & $28.34 \pm 1.60$ \\
\hline 6 & + & 30.43 & + & 30.97 & + & 27.33 & + & $29.58 \pm 1.96$ & 29.65 & + & 27.33 & + & Und & + & $28.49 \pm 1.64$ \\
\hline 7 & + & 30.54 & + & 31.11 & + & 27.41 & + & $29.69 \pm 1.99$ & 29.76 & + & 27.41 & + & Und & + & $28.59 \pm 1.66$ \\
\hline 8 & + & 31.12 & + & 31.53 & + & 28.25 & + & $30.37 \pm 1.79$ & 30.37 & + & 28.25 & + & Und & + & $29.31 \pm 1.50$ \\
\hline 9 & + & 31.44 & + & 31.92 & + & 28.54 & + & $30.61 \pm 1.83$ & 30.61 & + & 28.54 & + & Und & + & $29.58 \pm 1.46$ \\
\hline 10 & + & 31.81 & + & 32.16 & + & 28.63 & + & $30.63 \pm 1.94$ & 30.63 & + & 28.63 & + & Und & + & $29.63 \pm 1.41$ \\
\hline 11 & + & 32.09 & + & 32.39 & + & 28.83 & + & $30.87 \pm 1.97$ & 30.65 & + & 28.83 & + & Und & + & $29.74 \pm 1.29$ \\
\hline 12 & + & 32.12 & + & 32.48 & + & 28.87 & + & $31.16 \pm 1.99$ & 30.67 & + & 28.87 & + & Und & + & $29.77 \pm 1.27$ \\
\hline 13 & + & 32.15 & + & 32.55 & + & 29.12 & + & $31.27 \pm 1.88$ & 30.84 & + & 29.12 & + & Und & + & $29.98 \pm 1.22$ \\
\hline 14 & + & 32.25 & + & 32.93 & + & 29.33 & + & $31.50 \pm 1.91$ & 30.91 & + & 29.33 & + & Und & + & $30.12 \pm 1.12$ \\
\hline 15 & + & 32.59 & + & 33.29 & + & 29.4 & + & $31.76 \pm 2.07$ & 31.31 & + & 29.4 & + & Und & + & $30.36 \pm 1.35$ \\
\hline 16 & + & 32.68 & + & 33.46 & + & 29.43 & + & $31.86 \pm 2.14$ & 31.82 & + & 29.43 & + & Und & + & $30.63 \pm 1.69$ \\
\hline 17 & + & 32.79 & + & 33.52 & + & 29.63 & + & $31.91 \pm 2.07$ & 31.91 & + & 29.63 & + & Und & + & $30.77 \pm 1.61$ \\
\hline 18 & + & 33.05 & + & 33.86 & + & 30.56 & + & $32.49 \pm 1.72$ & 31.96 & + & 30.56 & + & Und & + & $31.26 \pm 0.99$ \\
\hline 19 & + & 33.32 & + & 33.92 & + & 30.7 & + & $32.65 \pm 1.71$ & 32.23 & + & 30.7 & + & Und & + & $31.47 \pm 1.08$ \\
\hline 20 & + & 33.65 & + & 34.06 & + & 31.11 & + & $32.94 \pm 1.60$ & 32.39 & + & 31.11 & + & Und & + & $31.75 \pm 0.91$ \\
\hline 21 & + & 33.66 & + & 34.1 & + & 32.32 & + & $33.56 \pm 0.93$ & 32.62 & + & 32.82 & + & Und & + & $32.76 \pm 0.14$ \\
\hline 22 & + & 33.94 & + & 34.66 & + & 32.38 & + & $33.66 \pm 1.17$ & 36.43 & + & 32.38 & + & Und & + & $34.41 \pm 2.86$ \\
\hline 23 & + & 34.36 & + & 34.71 & + & 33.67 & + & $34.25 \pm 0.53$ & 36.66 & + & 32.85 & - & Und & + & $34.76 \pm 2.69$ \\
\hline 24 & + & 35.35 & + & N/A & - & 33.67 & + & $34.51 \pm 1.19$ & 36.69 & + & 33.67 & - & Und & + & $35.18 \pm 2.14$ \\
\hline 25 & - & 36.96 & - & N/A & - & 37.27 & - & $37.12 \pm 0.22$ & 37.71 & - & 37.27 & - & Und & - & $37.49 \pm 0.31$ \\
\hline 26 & - & N/A & - & N/A & - & $\mathrm{N} / \mathrm{A}$ & - & & N/A & - & N/A & - & Und & - & \\
\hline 27 & - & N/A & - & N/A & - & N/A & - & & $\mathrm{N} / \mathrm{A}$ & - & N/A & - & Und & - & \\
\hline 28 & - & N/A & - & N/A & - & N/A & - & & N/A & - & N/A & - & Und & - & \\
\hline 29 & - & N/A & - & N/A & - & N/A & - & & N/A & - & N/A & - & Und & - & \\
\hline 30 & - & N/A & - & N/A & - & N/A & - & & N/A & - & N/A & - & Und & - & \\
\hline 31 & - & N/A & - & N/A & - & N/A & - & & N/A & - & N/A & - & Und & - & \\
\hline 32 & - & N/A & - & N/A & - & N/A & - & & N/A & - & N/A & - & Und & - & \\
\hline
\end{tabular}


The results gained in the first protocol were not perfectly homogeneous. In particular, Lab 2 produced a false negative. The variability comparison of the qPCR Probe protocol within the labs with respect to the expected (average) values, gave results that were significantly not different $(\mathrm{F}=0.76$; $0.68 ; 0.79 ; \mathrm{df}=23 ; p=0.05)$. The diagnostic sensitivity was $97.33 \%$, the diagnostic specificity reached $100 \%$, and the relative accuracy was $97.9 \%$.

The application of the qPCR SYBR Green protocol showed some differences between the experimental and expected values. Lab 3 and 2 provided one and two false negatives, respectively. In the variability comparison, two labs gave results that were significantly not different $(\mathrm{F}=0.61 ; 0.73$; $\mathrm{df}=23 ; p=0.05$ ). The third laboratory did not provide the Cq data but only the qualitative results. The diagnostic sensitivity was $96.10 \%$, the diagnostic specificity reached $100 \%$ (with no false positives), and the relative accuracy reached $97.3 \%$.

\subsection{Repeatability, Reproducibility, and LoD}

The checks for the repeatability and reproducibility (only for the frass samples of RLB) between the tests took place internally by Lab 1 . In both protocols, very low values (Table 4) were observed. In the qPCR Probe protocol, the repeatability values showed intervals between 5.19 and 1.99 and from 4.13 to 2.18 for reproducibility. For qPCR SYBR Green, the limit values (for repeatability) were 4.92 and 0.47 , while for reproducibility, the values were 4.37 and 1.78 .

Table 4. Repeatability and reproducibility of the real-time assays measured as the percentage coefficient of variation (\% CV).

\begin{tabular}{ccccccc}
\hline \multirow{2}{*}{ Sample } & \multicolumn{3}{c}{ qPCR Probe Protocol } & \multicolumn{3}{c}{ qPCR SYBR Green Protocol } \\
\cline { 2 - 5 } & \multicolumn{2}{c}{ Repeatability } & \multirow{2}{*}{ Reproducibility } & \multicolumn{2}{c}{ Repeatability } & \multirow{2}{*}{ Reproducibility } \\
\cline { 2 - 3 } & Assay 1 & Assay 2 & & Assay 1 & Assay 2 & \\
\hline 1 & 5.19 & 2.45 & 4.13 & 3.02 & 2.47 & 2.49 \\
2 & 3.19 & 4.85 & 3.76 & 2.73 & 2.28 & 2.35 \\
3 & 2.64 & 2.18 & 2.18 & 2.50 & 0.99 & 1.78 \\
4 & 2.92 & 3.94 & 3.13 & 4.07 & 0.79 & 2.67 \\
5 & 2.81 & 1.99 & 2.37 & 2.36 & 0.47 & 1.98 \\
6 & 3.06 & 3.82 & 3.10 & 2.44 & 0.44 & 1.96 \\
7 & 3.08 & 3.63 & 3.11 & 3.47 & 4.22 & 3.46 \\
8 & 3.04 & 2.16 & 2.36 & 3.75 & 3.52 & 3.26 \\
9 & 3.06 & 3.09 & 2.80 & 3.32 & 1.73 & 2.47 \\
10 & 3.88 & 4.16 & 3.71 & 4.92 & 4.82 & 4.37 \\
\hline
\end{tabular}

The analytical sensitivity showed a clear amplification with $10 \mathrm{ng} / \mu \mathrm{L}$ of the template. The lowest amount of RLB DNA that could be detected (LoD) was $0.016 \mathrm{ng} / \mu \mathrm{L}$ and $3.2 \mathrm{pg} / \mu \mathrm{L}$ with the Probe $\mathrm{qPCR}$ and the SYBR Green qPCR protocols, respectively.

\section{Discussion}

Wood-boring pests are considered one of the most successful groups of invasive pests transported worldwide in a variety of wood products [39]. The rapid diagnosis of xylophagous insects at points of entry or in the potential outbreak areas is of paramount importance to avoid dramatic ecological and economic consequences due to their establishment in new territories [40,41]. During the field monitoring activities, the availability of easy-to-handle morphological taxonomic keys could be a rapid and useful tool for identification of the species at immature stages. Unfortunately, the collected larvae may be in early developmental stages and may lack the diagnostic characteristics associated with later instars, upon which the relevant keys are based [42]. Moreover, larvae can be damaged during extraction attempts from the host plant. Currently, the diagnosis of RLB infestations is confirmed by the presence of adult specimens of the pest or by means of morphological and molecular analysis on larvae extracted from the wooden tissues of the infested plant $[7,11]$. 
Even the use of pheromone-based trapping devices that may support and orientate direct treeinspecting tasks in the invasion areas, thereby identifying new RLB outbreaks [43-46], retain some degree of uncertainty and do not solve misidentification due to cohabitation among native and invasive pests [11]. Once potentially infested trees are detected, the availability of non-invasive diagnostic tools to screen suspected RLB infestations may prevent unnecessary heavy plant injuries or plant destruction without the misuse of important economic resources in accordance with the other detection methods proposed for invasive wood-boring species [47,48].

To date, several diagnostic methods have been based on the indirect identification of insects through biological evidence like larval skins, [49], fecal pellets, [50], frass, and empty leaf mines [21-23].

The availability of such diagnostic tools for RLB may facilitate field and lab investigations related to phytosanitary emergencies caused by this priority quarantine pest whose biotic potential threatens European farmers [14]. Furthermore, the developed tool could lead to better-targeted insecticide treatments. It could also help complete the framework for an integrated management of RLB and may limit negative impacts on the productivity and sustainability of stone fruit production.

The presented diagnostic protocols using qPCR Probe and SYBR Green to identify RLB field outbreaks by means of larval frass achieved excellent results, discriminating all samples ascribed to this pest from those produced by other xylophagous species with $100 \%$ correspondence to available homologous reference sequences.

The diagnostic protocols carried out in the present study to investigate complex matrices such as insect frass should be used in tandem to ensure stronger results, as they are different and alternative techniques that produce amplicons related to different genomic regions.

The blind panel conducted in the involved laboratories, with the use of both protocols, reached values of sensitivity, specificity and accuracy between 96.1 and $100 \%$.

In the proposed diagnostic method, the choice and efficiency of the DNA extraction method is of paramount importance due to the relatively low amount of target DNA present in the frass. Moreover, the target DNA is difficult to amplify because of the presence of PCR inhibitors within the frass [22-25]. In our study, the frass analyzed was stocked at room temperature for at least four years without particular care. Nevertheless, the extraction of nucleic acids always yielded satisfactory results and good performance. Furthermore, this diagnostic protocol was also able to extract RLB DNA in 5-year-old frass, showing a prolonged shelf life of the fecal DNA, as already observed in other wood-boring species [22,23,48]. Despite this long shelf life, the exposed fecal DNA, in the frass accumulating on the ground near the trunk foot, easily undergoes degradation during a short period of time, as reported in another work on An. chinensis [22]. Therefore, a correct sampling procedure should be used to avoid contamination between frass typologies, even for RLB. Collectors must be able to recognize newly expelled frass from that produced long ago and exposed to environmental degradation factors. Only the former is useful and increases the chance of recovering fecal DNA suitable for PCR, thereby improving the validity of the proposed diagnostic method.

The $\mathrm{Cq}$ values related to the reactions of the different protocols tested via real-time PCR, in terms of their inclusiveness, diagnostic specificity, repeatability, and ring tests, showed variability but with good agreement between the two assays.

The detection limits were very low. Within the detection limits, the proposed protocols provided repeatable and reproducible results for all samples analyzed. Some variability, however, was found in the repeatability of the qPCR protocols. This fact can be reasonably explained by the presence of PCR inhibiting compounds in the frass matrix.

The robustness tests carried out gave excellent data for both the TaqMan probe and the SYBR Green-based technology, despite the starting matrix and the different operators, instruments, and master mixes used in the reactions. Similarly, the results obtained in the tests performed by different operators and with different instruments were comparable.

Finally, to ensure greater diagnostic specificity, the joint use of the two qPCR protocols is recommended in case of suspicion and/or the need for analytical confirmation. 


\section{Conclusions}

The obtained results show that an accurate and reliable diagnosis of RLB infestation through the analysis of larval frass collected in the field is conceivable. This approach offers a new diagnostic tool for phytosanitary surveys that can be used to support plant inspections and the early detection of RLB infestations at official points of entry, in nurseries, and during plant trading, as well as to ensure the correct implementation of pest suppression actions and eradication procedures, and to define the sustainable control methods to contain the threat.

Author Contributions: Conceptualization of the research approach, detailed laboratory methodologies, experimental designs for this study were developed and conducted by D.R., D.D.L., L.B. and L.S. All field work was accomplished by A.P.G., F.N., R.V.G. and A.T. Data curation and data mining reference assembly and manuscript formatting were done by D.R., A.P.G., F.N. and E.R. Writing of the original draft was prepared by D.R., F.N., A.P.G., E.R. and D.D.L. Overall funding acquisition and fund allocations were arranged by A.P.G. Blind Panel: D.R., D.D.L., A.T., L.B., L.C., E.B., P.S. and F.N. Revisions of manuscripts were completed by all authors. All authors have read and agreed to the published version of manuscript.

Funding: This work was partly supported by the CAMPANIA REGION, 2017-2019 Plan of Phytosanitary Action, URCoFi project (IV/2017 grant no. B76J17001050003).

Conflicts of Interest: The authors declare no conflict of interest.

\section{References}

1. EPPO_European Plant Protection Organization. Aromia bungii (AROMBU). EPPO Global Database. 2020. Available online: https://gd.eppo.int/taxon/AROMBU/distribution (accessed on 20 March 2020).

2. EPPO. First Report of Aromia bungii in Germany: Addition to the EPPO Alert List. EPPO Reporting Service. 2012. Available online: https://gd.eppo.int/reporting/article-1917 (accessed on 9 April 2020).

3. Hoerren, T. Another evidence of the Asian muskbeetle Aromia bungii (Faldermann. 1835) in Germany (Coleoptera: Cerambycidae. Cerambycinae). Entomol. Z. 2016, 126, 205-207. (In German)

4. Bayerische LfL. The Asian Musk Beetle Aromia bungii. 2016. Available online: https://www.lfl.bayern.de/ips/ pflanzengesundheit/142278/index.php (accessed on 9 April 2020).

5. EPPO. First Report of Aromia bungii in Italy. EPPO Reporting Service. 2012. Available online: https: //gd.eppo.int/reporting/article-2410 (accessed on 9 April 2020).

6. EPPO. Aromia bungii found for the first time in Lombardia Region. Italy. EPPO Reporting Service. 2013. Available online: https://gd.eppo.int/reporting/article-2649 (accessed on 9 April 2020).

7. Garonna, A.P.; Nugnes, F.; Espinosa, B.; Griffo, R.; Benchi, D. Aromia bungii, a new Asian worm found in Campania. Inf. Agrar. 2013, 69, 60-62. (In Italian)

8. Anonymous. The First Longicorn Beetle in Japan Confirmed in Aichi. Damaging Cherry and Japanese Apricot Trees. 2013. Available online: http://english.agrinews.co.jp/?p=482 (accessed on 4 April 2020).

9. Kano, M.; Nonaka, T.; Kiriyama, S.; Iwata, R. Aromia bungii (Coleoptera: Cerambycidae) an invasive cerambycid found at Soka Saitama Pref., Japan infesting cherry trees Cerasus $\times$ yedoensis 'Somei-yoshino'. For. Pests 2014, 63, 101-105, (In Japanese with English summary).

10. CABI. Aromia bungii. Invasive Species Compendium; CAB International: Wallingford, UK, 2020. Available online: www.cabi.org/isc (accessed on 20 March 2020).

11. De la Peña, E.; Schrader, G.; Vos, S. Pest survey card on Aromia bungii. EFSA Supp. Pub. 2019, 16, EN-1731. [CrossRef]

12. Wang, Q. Cerambycid pests in agricultural and horticultural crops. In Cerambycidae of the World: Biology and Pest Management; Wang, Q., Ed.; CRC Press: Boca Raton, FL, USA, 2017; pp. 409-562.

13. Ma, W.H.; Sun, L.Y.; Yu, L.G.; Wang, J.T.; Chen, J.Y. Study on the occurrence and life history in Aromia bungii (Faldermann). Acta. Agric. Boreali Sinica 2007, 22, 247-249.

14. Russo, E.; Nugnes, F.; Vicinanza, F.; Garonna, A.P.; Bernardo, U. Biological and molecular characterization of Aromia bungii (Faldermann. 1835) (Coleoptera: Cerambycidae) an emerging pest of stone fruits in Europe. Sci. Rep. 2020, 10, 7112. [CrossRef] [PubMed]

15. EPPO. Pest Risk Analysis for Aromia bungii. 2014. Available online: http://www.eppo.int/QUARANTINE/ Pest_Risk_Analysis/PRA_intro.htm (accessed on 9 April 2020). 
16. Cocquempot, C. Aromia bungii. EPPO datasheet on pests recommended for regulation. EPPO Bull. 2014, 45, 4-8.

17. Carella, D. Regional Action Plan for the Control of the Longhorn Beetle Aromia bungii-VII Update; Executive Decree n. 134. Bollettino Ufficiale della Regione Campania. 2019. Available online: http://agricoltura.regione. campania.it/difesa/files/DRD_134-18-11-19.pdf (accessed on 7 May 2020). (In Italian).

18. European Union. Commission Implementing Decision (EU) 2018/1503 of 8 October 2018 as regards measures to prevent the introduction into and the spread within the Union of Aromia bungii (Faldermann). Off. J. Eur. Union. 2018, 254, 9-18.

19. Calderon-Cortes, N.; Quesada, M.; Cano-Camacho, H.; Zavala-Paramo, G. A simple and rapid method for DNA isolation from xylophagous insects. Int. J. Mol. Sci. 2010, 11, 5056-5064. [CrossRef]

20. Kethidi, D.R.; Roden, D.B.; Ladd, T.R.; Krell, P.J.; Retnakaran, A.; Feng, Q. Development of SCAR markers for the DNA-based detection of the Asian long-horned beetle Anoplophora glabripennis (Motschulsky). Arch. Insect. Biochem. Physiol. 2003, 52, 193-204. [CrossRef]

21. Mlynarek, J.J.; Kim, J.H.; Heard, S.B. Identification of leaf-mining insects via DNA recovered from empty mines. FACETS 2016, 1, 217-224. [CrossRef]

22. Ide, T.; Kanzaki, N.; Ohmura, W.; Okabe, K. Molecular Identification of an invasive wood-boring insect Lyctus brunneus (Coleoptera: Bostrichidae: Lyctinae) using frass by Loop-mediated isothermal amplification and nested PCR assays. J. Econ. Entomol. 2016, 109, 1410-1414. [CrossRef] [PubMed]

23. Ide, T.; Kanzaki, N.; Ohmura, W.; Okabe, K. Molecular Identification of the western Drywood Termite (Isoptera: Kalotermitidae) by Loop-Mediated Isothermal Amplification of DNA from fecal pellet. J. Econ. Entomol. 2016, 109, 2234-2237. [CrossRef] [PubMed]

24. Nagarajan, R.P.; Goodbla, A.; Graves, E.; Baerwald, M.; Holyoak, M.; Schreier, A. Noninvasive genetic monitoring for the threatened valley elderberry longhorn beetle. PLOS ONE 2020. [CrossRef] [PubMed]

25. Strangi, A.; Sabbatini Peverieri, G.; Roversi, P.F. Managing outbreaks of the citrus long-horned beetle Anoplophora chinensis (Forster) in Europe: Molecular diagnosis of plant infestation. Pest Manag. Sci. 2013, 69, 627-634. [CrossRef]

26. Duffy, E.A.J. A Monograph of the Immature Stages of Oriental Timber Beetles (Cerambycidae); London British Museum (Natural History): London, UK, 1968; p. 434.

27. Gressitt, J.L. Destructive long-horned beetle borers at Canton. China. Spec. Publ. Lingnan. Nat. Hist. Surv. 1942, 1, 1-60.

28. Švácha, P.; Danilevsky, M.L. Cerambycoid larvae of Europe and Soviet Union (Coleoptera, Cerambycoidea). Part II. Acta Univ. Carolinae Biol. 1988, 31, 121-284.

29. Li, R.; Mocka, R.; Huang, Q.; Abad, J.; Hartung, J.G.; Kinarda, G. A reliable and inexpensive method of nucleic acid extraction for the PCR-based detection of diverse plant pathogens. J. Virol. Methods 2008, 154, 48-55. [CrossRef]

30. Weller, S.A.; Elphinstone, J.G.; Smith, N.C.; Boonham, N.; Stead, D.E. Detection of Ralstonia solanacearum Strains with a Quantitative, Multiplex, Real-Time, Fluorogenic PCR (TaqMan) Assay. Appl. Environ. Microbiol. 2000, 66, 2853-2858. [CrossRef] [PubMed]

31. loos, R.; Fourrier, C.; Iancu, G.; Gordon, T.R. Sensitive detection of Fusarium circinatum in pine seeds by combining an enrichment procedure with a Real-Time PCR using dual-labeled probe chemistry. Phytopathology 2009, 99, 582-590. [CrossRef]

32. Katoh, K.; Standley, D.M. MAFFT multiple sequence alignment software version 7: Improvements in performance and usability. Mol. Biol. Evol. 2013, 30, 772-780. [CrossRef] [PubMed]

33. Kearse, M.; Moir, R.; Wilson, A.; Stone-Havas, S.; Cheung, M.; Sturrock, S.; Buxton, S.; Cooper, A.; Markowitz, S.; Duran, C.; et al. Geneious Basic: An integrated and extendable desktop software platform for the organization and analysis of sequence data. Bioinformatics 2012, 28, 1647-1649. [CrossRef] [PubMed]

34. EPPO. 2017 PM 7/76 (4) Use of EPPO diagnostic protocols. EPPO Bull. 2017, 47, 7-9. [CrossRef]

35. EPPO. PM 7/98 (4) Specific requirements for laboratories preparing accreditation for a plant pest diagnostic activity. EPPO Bull. 2019, 49, 530-563. [CrossRef]

36. Blaser, S.; Diem, H.; von Felten, A.; Gueuning, M.; Andreou, M.; Boonham, N.; Tomlinson, J.; Müller, P.; Utzinger, J.; Frey, J.E.; et al. From laboratory to point of entry: Development and implementation of a loop-mediated isothermal amplification (LAMP)-based genetic identification system to prevent introduction of quarantine insect species. Pest. Manag. Sci. 2018, 74, 1504-1512. [CrossRef] 
37. Dhami, M.K.; Dsouza, M.; Waite, D.W.; Anderson, D.; Li, D. Real time PCR Assay for the Identification of the Brown Marmorated Stink Bug (Halyomorpha halys). Front. Mol. Biosci. 2016. [CrossRef]

38. Koohkanzade, M.; Zakiaghl, M.; Dhami, M.K.; Fekrat, L.; Namaghi, H.S. Rapid identification of Bactrocera zonata (Dip.: Tephritidae) using TaqMan real time PCR assay. PLoS ONE 2018. [CrossRef]

39. Hulme, P.E. Trade. transport and trouble: Managing invasive species pathways in an era of globalization. J. Appl. Ecol. 2009, 46, 10-18. [CrossRef]

40. Hérard, F.; Maspero, M. History of discoveries and management of the citrus longhorned beetle Anoplophora chinensis in Europe. J. Pest Sci. 2019, 92, 117-130. [CrossRef]

41. Herms, D.A.; McCullough, D.G. Emerald Ash Borer Invasion of North America: History Biology Ecology Impacts and Management. Annu. Rev. Entomol. 2014, 59, 13-30. [CrossRef] [PubMed]

42. Pennacchio, F.; Sabbatini, P.G.; Jucker, C.; Allegro, G.; Roversi, P.F. A key for the identification of larvae of Anoplophora chinensis. Anoplophora glabripennis and Psacothea hilaris (Coleoptera Cerambycidae Lamiinae) in Europe. J. Zool. 2012, 95, 57-65.

43. Fukaya, M.; Kiriyama, S.; Yasui, H. Mate-location flight of the red-necked longicorn beetle. Aromia bungii (Coleoptera: Cerambycidae): An invasive pest lethal to Rosaceae trees. Appl. Entomol. Zool. 2017, 52, 559-565. [CrossRef]

44. Yasui, H.; Fujiwara-Tsujii, N.; Yasuda, T.; Fukaya, M.; Kiriyama, S.; Nakano, A.; Watanabe, T.; Mori, K. Electroantennographic responses and field attraction of an emerging invader the red-necked longicorn beetle Aromia bungii (Coleoptera: Cerambycidae) to the chiral and racemic forms of its male-produced aggregation-sex pheromone. Appl. Entomol. Zool. 2019, 54, 109-114. [CrossRef]

45. Germinara, G.S.; Pistillo, O.M.; Griffo, R.; Garonna, A.P.; Di Palma, A. Electroantennographic responses of Aromia bungii (Faldermann. 1835) (Coleoptera: Cerambycidae) to a range of volatile compounds. Insects 2019, 10, 274. [CrossRef]

46. Zou, Y.; Hansen, L.; Xu, T.; Teale, S.A.; Hao, D.; Millar, J.C. Optimizing pheromone-based lures for the invasive red-necked longhorn beetle. Aromia bungii. J. Pest Sci. 2019, 92, 1217-1225. [CrossRef]

47. Finley, K.; Chhin, S. Forest health management and detection of invasive forest insects. Resources 2016, 5, 18. [CrossRef]

48. Wilson, A.D.; Forse, L.B.; Babst, B.A.; Bataineh, M.M. Detection of Emerald ash borer infestations in living green ash by noninvasive electronic-nose analysis of wood volatiles. Biosensors 2019, 9, 123. [CrossRef]

49. Wu, Y.; Trepanowski, N.F.; Molongoski, J.J.; Reagel, P.F.; Lingafelter, S.W.; Nadel, H.; Myers, S.W.; Ray, A.M. Identification of wood-boring beetles (Cerambycidae and Buprestidae) intercepted in trade associated solid wood packaging material using DNA barcoding and morphology. Sci. Rep. 2017, 7, 40316. [CrossRef]

50. Rytkönen, S.; Vesterinen, E.J.; Westerduin, C.; Leviäkanga, E.J.; Vatka, E.; Mutanen, M.; Älimäki, P.; Hukkanen, M.; Suokas, M.; Orell, M. From feces to data: A metabarcoding method for analyzing consumed and available prey in a bird-insect food web. Ecol. Evol. 2019, 9, 631-639. [CrossRef] 